\title{
The Fallacies of Corporate Investment Appraisal: A discussion of Share Price Maximization
}

\author{
Wang Xue \\ College of Airport Engineering and Transportation Management \\ Civil Aviation Flight University of China \\ Guanghan, China \\ Janewang0128@126.com
}

\begin{abstract}
For a long time, share price growth has been regarded as the primary benchmark of success in management decision-making for listed enterprises. However, this viewpoint may lead to bias of the management objective, underinvestment in capital budgeting, and inappropriate reward scheme for management. Based on the fundamental theory of corporate finance, the paper tends to find out the fallacies of share price maximization theory and some inappropriate criteria for investment appraisal. The theory of Capital Market Efficiency, Capital Structure, equations of Net Present Value and decision making criteria such as Payback and Internal Rate of Return will be used to support the analysis. The paper illustrates that although share price has important effects on financial management of a listed corporate, it may be misleading and cause fallacies in management. Some frequently used criteria may result in mistakes in investment decision making. It is important that managers pursue a valid objective and make investment decisions based on rational criteria. In summary, this paper gives financial managers general suggestions on corporate goal setting and capital budgeting but still the problems can be solved by further studies.
\end{abstract}

Keywords-Share Price Maximization; Company Objective; Market Efficiency; Investment Decision; Net Present Value

\section{INTRODUCTION}

As a corporate manager, the most fundamental tasks are pursuing a valid goal for the corporate and making investment decisions based on appropriate criteria. Any mistakes in fulfilling these tasks may result in loss or even bankruptcy to the corporate. Therefore, it is important to pursue a valid objective and find appropriate benchmarks of success in management decision-making.

In a traditional point of $v$ iew, financial managers in a listed corporation make decisions for the shareholders because the shareholders own and control the corporation. Therefore, the primary objective of the corporation is to add value for the shareholders [1]. As a result, share price maximization (SPM) has been viewed as a financial objective in many companies for a long time. However, it is debated that SPM as a benchmark of success in management decision-making is irrational even misleading. Some frequently used criteria such as IRR and Payback in investment appraisal are also flawed. The paper will find out the fallacies of share price effects in corporate financial management such as evaluation of corporate value, capital budgeting and investment decision-making.

\section{MARKET AND SHARE PRICE}

Before discussing the validity of share price maximization in reality, the efficient-market hypothes is should be introduced first.

\section{A. Efficiency of Capital Market}

As Ross et al mentioned, "an efficient capital market is one in which stock prices fully reflect available information" [1]. The efficient level of a capital market is determined by precise definition of information [2]. Information is commonly classified into three types: information on past prices, available information in public and all information including the former two types and all information in private. According to different effects of information types, the market can be categorized to the weak form efficiency, semi-strongform efficiency and strong-form efficiency [3]. If the capital market is strong-form efficient, the share price will fully reflect all the information in the market even some information is hold by some company insiders.

The efficiency level of one capital market is related to many factors, such as the government policies, the maturity of the market, the technical technologies used for the market and the rationality of the major investors. In a strong efficient market, share price is able to represent the corporate value to some extent while in a weak efficient market share price can be overvalued or undervalued for a long period due to the late arrival or even false information. Before estimating share prices, an investigation should be taken first to define the efficiency level of the capital market especially in emerging or less-developed markets.

\section{B. Product Market and Share Price}

In a perfectly competitive product market, positiveNPV investments are hard to find. Therefore, there can be no expectation to earn abnormal return in stock investment [4]. The company's share price will remain a horizontal line after its flotation. 
When the market is not perfectly competitive, there seems to be opportunities for some firms to gain abnormal return by exploiting positive-NPV projects. However, as Findlay and Williams mentioned, even these excess return opportunities existed, investors still could not expect abnormal return on the share price growth [5].

The shares are priced by the stock market according to the net present values of all projects over the firm's life time. The pricing function of stock market refers to the expectations of the future by investors. Investors make the investment decision according to the firm's potential, which can be represented by its future projects. Share price also depends a lot on the market efficiency as mentioned before. In this scheme, the market has an ability to predict the future stream of Net Present Values (NPVs) of all the projects rather than waiting for them to occur. That means the share price reflect not only current projects but also future earnings potential. When the stock market has a perfect foresight, the potential of the firm's future abnormal return is all discounted into the initial share price and generation shareholders can expect to gain nothing but normal return for risk. NPV can be calculated as follows under a certain discount rate (r) if future cash flows are categorized into an initial investment $\left(\mathrm{I}_{0}\right)$ and periodical earnings $\left(\mathrm{E}_{\mathrm{t}}\right)$ along its lifetime (T).

$$
N P V=\sum_{t=1}^{T} \frac{C F_{t}}{(1+r)^{t}}=-I_{0}+\sum_{t=1}^{T} \frac{E_{t}}{(1+r)^{t}}
$$

The relationship between share price, streams of NPVs and earnings can be shown as follows.

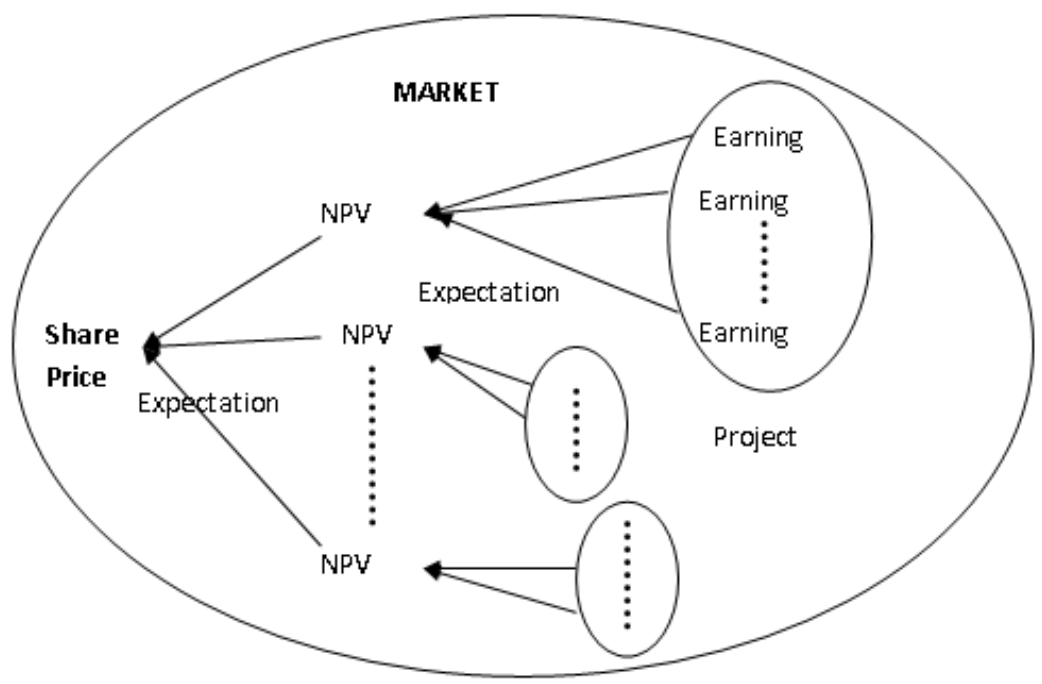

Figure 1. Relationship between share price, NPVs and earning

It is doubted by Pena [6] that the information deficiency could last long due to information cost. However, as Copeland and Weston suggested, the efficiency of market is relative to information which excludes cost of acquiring, transmitting and evaluating messages [2]. For investors, spending money on security analysis before investment and random selection of shares are just alternative strategies which are identical. Even when the market predicts the future imperfectly, the share price will reflect the market estimation to the biggest extent. There can be equal certainty for the market to overestimate and underestimate the price, so abnormal return on share price growth still cannot be expected.

\section{FALLACIES OF SPM}

According to the set-of-contracts theory [7], a firm can be viewed as a set of contracts while the shareholders as equity investors are the principals of the firm. The managers as the agents in the corporate firm will usually attempt to maximize the shareholder's wealth by taking actions that increase the value per share of the firm's stock. Arnold also suggested that the goal of a firm is to maximize its shareholders' wealth because shareholders own the firm, and thus deserve any surplus the firm produces [8]. It is then stated in many textbooks that the financial objective of the firm is to maximize share price. However SPM can lead to severalfallacies.

\section{A. Underinvestment bias leaded by SPM objective}

The thought of share price maximization may lead to underinvestment and consequently result in loss of firm value. There are three fallacies leading to underinvestment which are the positive-NPV fallacy, the reinvestment fallacy and investment efficiency fallacy.

1) Firm value and share price

Denote $\mathrm{P}$ as the firm's share price, $\mathrm{V}$ as firm value. For a pure equity firm, its firm value can be simply calculated as:

$$
\mathrm{V}=\mathrm{N} \times \mathrm{P} \text {. }
$$


It can be seen that firm value and share price cannot be equaled. The company cannot expect share price growth to add firm value [4]. Sometimes the two elements may even contradict to each other. Though growth in $\mathrm{V}$ cannot be expected to result from growth in $\mathrm{P}$, managers cannot add the firm value at the expense of share price. As a result, managers may give up some projects which can add value to the firm but bring down the share price.

In the real world, the value of the firm (V) is defined as

$$
\mathrm{V} \equiv \mathrm{B}+\mathrm{S} \text {. }
$$

Where $B$ is the market value of the debt and $S$ is the market value of the equity. The capital structure can be shown as the Fig. 2.

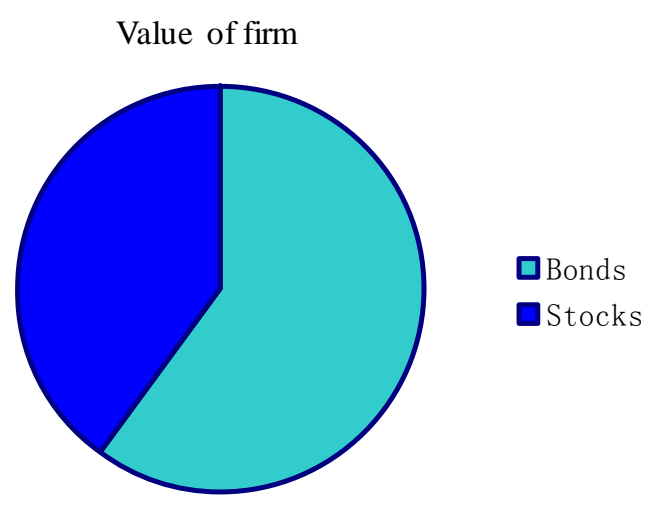

Figure 2. Pie Model of Capital Structure

The capital structure of a corporate should be rationally leveraged by choosing a debt-equity ratio that makes the total value maximu m.

Taking taxes and bankruptcy costs into consideration, the composition of the firm's value is illustrated in Fig. 3 and should be calculated as in Equation (4).

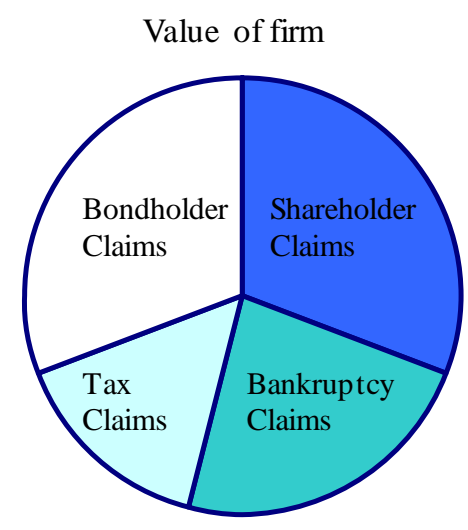

Figure 3. The Pie Model with Real-world Factors

The value of the firm will be paid out to bondholders, shareholders, taxes (government) and bankruptcy claims.

$$
\mathrm{V}=\mathrm{B}+\mathrm{S}+\mathrm{G}+\mathrm{A} \text {. }
$$

Where $\mathrm{G}$ stands for the government and taxes while $\mathrm{A}$ stands for bankruptcy costs.

In the real world, a firm's value is not only related to share price but also many other factors. According to the equation above, SPM is not the only way to add firm, but may be a barrier for managers to add the firm value by changing other factors. If putting share price in the first place when making a decision, some profitable projects may be rejected.

2) Feasibility of zero-NPV projects

It is mentioned in Smallwood's paper that he had never known a project with zero-NPV to be accepted and he regarded abnormal return as a precondition of investment [9]. To his latter argument, it has been discussed that even when the market is not that efficient to estimate the share price perfectly, the fluctuation of the price is due to the unexpected events rather than potential of abnormal earnings.

As to the former point, it is exactly how the companies act to result in underinvestment. It is cited in Arnold's book that Michael Heseltine, the one-time president of the Board of Trade, complained that "Business are not investing enough because of their excessive expectations of investment returns." [8] Many companies expect too high a rate of return so that ignore zero-NPV investments completely.

Under the objective of share price maximization, firms tend to fall in the positive-NPV fallacy. There is no doubt that positive-NPV projects are more welcome than zeroNPV ones. However, positive-NPV cannot be the precondition of investments. Whether subscribe to SPM or not, many managers and scholars take no account of zero$\mathrm{NPV}$ investments. In fact, in a perfect market, companies can only expect to invest in zero-NPV projects to add the firm value.

From another perspective, although projects with zeroNPV seem to make no economic benefits, they can however bring out social benefits. Managers should make sure the role the firm plays before evaluate the projects. Sometimes even negative-NPV projects are accepted to fulfill some social responsibilities or to solve non-financial problems.

3) The firm's objectives

According to the discussion above, it can be concluded that the overall objective of the firm is to maximize firm value subject to maximize the share price or $M A X V_{t} \mid M A X P_{t}$ no matter whether the market is perfectly competitive or not. This objective implicates that the capital budgeting objective of a firm is to take nonnegative-NPV projects as many as possible in order to gather capital.

\section{B. SPM leads to misjudgement of management}

When some firms set their objective as SPM, they view share price growth as a criterion of management in consequence. This is in fact meaningless because managers cannot be expected to increase share price at all.

1) Managers can not be judged by share price growth

Due to the market's prediction, a stock is priced taking into account all the potential abnormal earnings including management performance at the very beginning. In other words, a firm's management quality has been reflected in its share price. The expectation of earning abnormal return 
by choosing a good managed firm instead of a poor managed one in fact makes no sense.

This does not mean expecting comparable performance from "badly managed" companies to "well managed" companies [10]. Of course good managers are more likely to perform better than the poor ones. However, this performance potential has been discounted into the share price and if there is error of the market prediction, the chance of share price growth and decrease equal even when the firm is well managed.

Besides, according to an analysis of performance pay over 2,000 CEOs, it is suggested by Jensen and Murphy that the relation between $\mathrm{CEO}$ wealth and shareholder wealth is small [11]. Therefore, it is nonsense to relate share price growth to management reward scheme.

Share price growth can be used as an incentive force to managers but is never rational to be an assessment of management, either reward basis.

2) Validassessments of management

According to the overall objective of the firm, managers should exploit projects with positive and zero NPVs as many as possible. Therefore, management performance should be assessed primarily by reference to the number of projects undertaken and NPVs not relating to the share price or whether the performance of the firm is improved while the share price remain flat or increase.

\section{CRITERIA OF INVESTMENT DECISIONS}

Besides a valid overall objective for the company, there should be rational criteria for financial managers to make appropriate decisions when choosing projects. Many textbooks suggest that the ideal criterion of capital appraisal is a combination of NPV, IRR and sometimes Payback. NPV is undoubtedly the best valuation method for new projects. The following content will discuss the rationality of the other two especially IRR.

\section{A. Payback}

Payback is defined as a measure of projects from the perspective of how long it takes to recoup the initial investment [12]. As most textbooks referred, the two weaknesses of Payback are that it ignores the time value of money (Static Payback time) and streams of cash flows beyond the payback period.

However, the inherent flaw of Payback is that it is in fact a thought of anti-investment. Even it can be amended to discount Payback and reflect the time value of money, it still implicates that the firm should get the investment money back as soon as possible. If payback is the primary criterion when evaluating projects, short term investment will definitely be chosen rather than long term ones because the investment capital can be recovered sooner. In that case, managers will reject long term investments even they contribute to the firm value. To achieve the financial objective, the company should invest as much and as long as possible.

\section{B. IRR}

IRR, Internal rate of return, is the "annualized effective compounded return rate" or rate of return that makes the NPV of all cash follows from an investment equal to zero [1]. It is widely used and often be viewed as an alternative way of NPV.

$$
N P V=\sum_{n=0}^{N} \frac{C_{n}}{(1+r)^{n}}=0
$$

Given the investment period (n), cash flows $C_{n}$ and the total number of periods N, IRR (r) can be calculated.

But the calculation result may have some shortcomings: IRR does not exist, multiple IRR exist, IRR is incompatible with NPV [13]. Moreover, IRR cannot be used to value projects unless they are strictly identical. To prove this point, the rationing and non-rationing of the capital should be mentioned first.

\section{1) Rationing and Nonrationing}

It is misconceived by many people that the market is rationing. They think that because of short of capital, companies have limited capital to invest in the projects. However, as long as the company has a project to assess, it indicates that there is enough capital to undertake this project.

\section{2) Flaws of IRR}

It is generally argued that flaws of IRR are multiple rates of return and the scale problem [1]. Actually if IRR is valid, the multiple rates of return will not affect the decision making. The only difference between it and the single rate of return is that the value of IRR is a range rather than a point.

To the scale problem, the textbooks suggest that an incremental IRR approach can solve it. Though sounds reasonable, this approach in fact falls into the reinvestment fallacy. In a non-rationing environment, the company will not lack the capital of the incremental investment. It is meaningless to compare the incremental IRR with the small budget IRR. Therefore, this method is not advisable.

The real problem of IRR approach is from its substantial fallacy. IRR requires the projects to be compared strictly having equal lives, equal outlays and same cash patterns. This requirement can only be achieved in the securities market. In a product market, IRR can never be used to rank projects. However as a traditional investment appraisal criterion, IRR is not abandoned due to the shortages but revised and used to introduce new criteria based on it such as AIRR in recent years [14].

\section{Rational criteria for decision making}

To summarize, NPV is the only valid measurement of investments. IRR cannot be used because its scale problem while Payback result in anti-investment. Use IRR as a supplement of NPV will only be conflicting and misleading.

\section{CONCLUSION}

It is important for firms to set a rational objective and choose appropriate decision criteria when valuing investment projects. SPM is misleading and cannot be used as the primary benchmark of management success. Instead of the widely accepted SPM, companies should take firm value maximizing subject to maximize share price as their objective. In consequence, managers' performance cannot be judged entirely by the share price growth. To reach the firm's overall objective, valid criteria of investment appraisal is essential. NPV should be the prime measure of investment decision. IRR and Payback can be used until the flaws are correctly revised and not conflict with NPV. 


\section{ACKNOWLEDGMENT}

The author is grateful to the anonymous referees, to the family and friends who help and support me along the time.

\section{REFERENCES}

[1] Ross, S.A., Westerfield, R.W., and Jaffe, J., Corporate Finance [M], 9th ed., The McGraw-Hill, 2010, pp. 71-95.

[2] Copeland, T.E. and Weston, J.F., Financial Theory and Corporate Policy [M],3rd ed., Addison-Wesley Publishing Company, 1998.

[3] Fama, E.F., "Efficient capital markets: A review of theory and empirical work" [J], Journal of Finance, May. 1970, pp.383-417.

[4] Keane, S.M., "A reappraisal of share price maximization as a corporate financial objective" [J], European Journal of Finance, Vol. 1, 1995, pp. 1-17.

[5] Findlay, M. and Williams, E., "Owners' Surplus, the Marginal Efficiency of Capital and Market Equilibrium" [J], Journal of Business Finance and Accounting, Spring. 1979, pp.2-8.

[6] Pena, J.I., "Comment" [J], The European Journal of Finance, Vol. 1, 1995, pp. 18-20.
[7] M. C. Jensen and W. Meckling, "Theory of the Firm: Managerial Behavior, Agency Costs and Ownership Structure" [J], Journal of Financial Economics Vol. 3, 1976.

[8] Arnold, G., Corporate Financial Management [M], 5rd ed., Pearson Education Limited, 2012, pp. 51-60.

[9] Smallwood, C.R., "Comment" [J], The European Journal of Finance, Vol. 1, 1995, pp. 21-25.

[10] Quick, G., "Comment: An analyst's reaction" [J], The European Journal of Finance, Vol. 1, 2011, pp.26-30.

[11] Jensen, M., and Murphy, K., "Performance pay and topmanagement incentives" [J], Journal of Political Economy, Vol. 98, 1990, pp. 225-64.

[12] Shapiro, A.C., Capital Budgeting and Investment Analysis [M], Pearson Prentice Hall, 2004, p. 18.

[13] Guerra, M.L., Magni, C.A. and Stefanini, L., "Interval and fuzzy Average Internal Rate of Return for investment appraisal", Fuzzy Sets and Systems, Vol. 257, Dec. 2014, pp. 217-241.

[14] Altshuler, D., and Magni, C.A., "Why the IRR is not the rate of return for your investment- introducing AIRR to the real estate community" [J], Real Estate Portf. Manag., Vol. 18(2), 2012, pp. 28 . 